\title{
Population differentiation, antifungal susceptibility, and host range of Trichophyton mentagrophytes isolates causing recalcitrant infections in humans and animals
}

\author{
Sebastian Gnat ${ }^{1}$ D $\cdot$ Dominik $Ł a g o w s k i^{1} \cdot$ Aneta Nowakiewicz $^{1} \cdot$ Marcelina Osińska $^{1} \cdot$ Łukasz Kopiński $^{2}$
}

Received: 28 April 2020 / Accepted: 10 June 2020 / Published online: 30 June 2020

(C) The Author(s) 2020

\begin{abstract}
The major problems in determining the causative factors of the high prevalence of dermatophytoses include the lack of a wellstandardized antifungal susceptibility testing method, the low consistency of in vitro and clinical minimal inhibitory concentration values, the high genomic diversity of the population, and the unclear mechanism of pathogenicity. These factors are of particular importance when the disease is recalcitrant and relapses. Herein, we identified and characterized Trichophyton mentagrophytes isolates obtained from therapy-resistant cases in humans and animals. We used genomic diversity analysis of 17 human and 27 animal clinical isolates with the MP-PCR technique, determined their phenotypic enzymatic activity and host range, and performed antifungal susceptibility testing to currently available antifungal drugs from various chemical groups. Genomic diversity values of $35.3 \%$ and $33.3 \%$ were obtained for clinical isolates from humans and animals, respectively, yet without any relationship to the host species or antifungal drug to which resistance in therapy was revealed. The highest activity of keratinase enzymes was recorded for fox, guinea pig, and human hairs. These hosts can be considered as the main species in the host range of these isolates. A phenyl morpholine derivative, i.e. amorolfine, exhibited superior activity against strains obtained from both humans and animals with the lowest $\mathrm{MIC}_{50}$. Interestingly, high compliance of terbinafine in vitro resistance with clinical problems in the treatment with this substance was shown as well. The high resistance of dermatophytes to drugs is the main cause of the recalcitrance of the infection, whereas the other features of the fungus are less important.
\end{abstract}

Keywords Antifungal resistance $\cdot$ Dermatophytes $\cdot$ Genomic diversity $\cdot$ Pathogenicity $\cdot$ Trichophyton mentagrophytes . Therapy $\cdot$ Public health $\cdot$ Keratinolytic activity

\section{Introduction}

Dermatophytes are the most commonly encountered fungi in humans and other vertebrates spreading through direct or indirect contacts with infected individuals and soil $[1,2]$. Epidemiological studies have documented a varied prevalence

Sebastian Gnat

sebastian.gnat@up.lublin.pl

Dominik Łagowski

dlagowsky@gmail.com

1 Faculty of Veterinary Medicine, Institute of Biological Bases of Animal Diseases, Department of Veterinary Microbiology, University of Life Sciences, Akademicka 12, 20-033 Lublin, Poland

2 Faculty of Agrobioengineering, Department of Management and Marketing, University of Life Sciences, Dobrzanskiego 37, 20-626 Lublin, Poland rate of dermatophytosis ranging from 14 to $26.8 \%$ in North America, Asia, and Europe and from 5 to $31.6 \%$ in Africa (Ethiopia, Kenya, Nigeria, and Tanzania) [3-7]. An alarming upward trend in the incidence of superficial dermatophytosis has been especially noticed in Europe and Asia over the past 5-10 years [8,9]. Although the high prevalence of dermatophytosis is a consequence of climate change and new living habits of society, a dramatic change in the clinical features of patients is also noted, as these infections are characterized by recalcitrant response to treatment and increasing relapse rates $[10,11]$. The cause of this phenomenon is not yet clear.

Considering the enormous number of taxonomic differences between dermatophytes that can be tested and the importance of species-level identification, the "gold standard" to use for routine mycological identification has still become the topic of a debate, and no uniform position of microbiologists has been developed $[8,12,13]$. Nonetheless, the advent of 
molecular methods in mycology facilitates identification of dermatophytes to the species level in a rapid and accurate manner [14-16]. However, other major problems remain, i.e. the lack of a well-standardized antifungal susceptibility testing method and the low consistency of in vitro and clinical minimal inhibitory concentration values [16-21]. In addition, although many studies of the mechanism of the pathogenicity of dermatophytes have been carried out over the years, there have been no concrete proposals whether it is possible to construct a profile of animal hosts susceptible to individual species of dermatophytes [22-25]. In this context, it is difficult to clearly determine whether the growing prevalence of dermatophytoses is caused only by changes observed in the natural environment and lifestyles or also by increased host sensitivity, a higher degree of dermatophyte pathogenicity, or the weakness of the currently available antifungal arsenal $[18$, 19, 22, 26].

Recent studies have demonstrated emerging predominance of members of the Trichophyton mentagrophytes species complex as the causative organisms in many cases of dermatophytoses $[9,18,27-30]$. Trichophyton mentagrophytes is primarily a zoophilic dermatophyte which often attacks humans through direct or indirect transmission from animals and can rarely survive saprophytically in the soil $[1,2]$. Infections caused by this species have been reported in a large number of wild and domestic animals including pets (guinea pigs, hamsters, rabbits, chinchillas) and fur animals (foxes, ferrets, wolf, mink) [29, 31, 32]. Interestingly, zoophilic fungal infections caused by T. mentagrophytes commonly occur especially in 3-7-year-old children and the elderly through purchase of asymptomatic pet carriers in zoological shops [33, 34].

Herein, we identified and investigated recalcitrant T. mentagrophytes infections in humans and animals. The aim of this study was to analyse the clinical isolates of dermatophytes in terms of their genomic diversity, phenotypic degree of pathogenicity, and in vitro susceptibility to antifungal drugs.

\section{Materials and methods}

\section{Patient details and identification}

Dermatophytes were detected from skin scrapings and hairs of 24 humans and 35 animals who had previously received oral and topical treatment for a period of at least 28 days (Table 1 ). None of the patients at that time took any other medications or received immunosuppressive therapy. Cases of infection were diagnosed between 2018 and 2019 in Poland. Tinea capitis: $n=15(62.5 \%)$ was the predominant clinical form in the human infections followed by tinea corporis: $n=7(29.2 \%)$ and tinea unguium: $n=2(8.3 \%)$. In the animals, ringworm located around the head and neck: $n=17$ (48.6\%), on the torso: $n=8$ (22.9\%), and in multiple sites on the body: $n=9(25.7 \%)$ was reported. In turn, dermatophytes were isolated from 17 (70.8\%) human and $27(77.1 \%)$ animal samples that were positive in the real-time PCR tests. The sample was collected from lesion margins. Detection and identification of dermatophytes in the dermatological material from the patients was conducted using the real-time PCR assay according to Ohst et al. [35]. Reactions with pan-dermatophyte primers (F: 5'A G C G C Y C G C C GR A G G A - 3'; R : $5^{\prime}$ - GA T T CACGGAATTCTGCAATTCAC-3') and species-specific primers (F: 5'-CGGCGAGCCTCTCTTTAGT-3'; R: 5'GATTCACGGAATTCTGCAATTCAC-3') targeting ITS1, ITS2, and 5.8S rDNA gene sequences in combination with TaqMan probes (Derm5.8S: CGCATTTCGCTGCG TTCTTCATC) were made to identify clinical isolates. DNA isolation and real-time PCR were carried out using a DNeasy Blood \& Tissue Kit and a Quanti Tect SYBR green PCR master mix (Qiagen, Hilden, Germany), respectively. A samples with dermatophyte identified in the real-time technique were directed to isolation of cultures. The species identification for full confirmation of the taxonomic position was based on macro- and microscopic examination according to de Hoog et al. [36] (Fig. 1).

\section{Genetic diversity of dermatophyte isolates}

The genetic diversity of the clinical isolates was performed with the melting point PCR (MP-PCR) method optimized and modified for dermatophytes [31]. Briefly, the first step was the digestion of the genomic DNA isolated from the cultures (phenol-chloroform method [37]) using HindIII (Thermo Fisher, Waltham, USA) endonuclease. Next, an adaptor, i.e. a mixture of two oligonucleotides Helper and Ligated (Helper: 5'-AGCTGTCGACGTTGG-3', Ligated: 5'CTCACTCTCACCAACAACGTCGAC-3'), was ligated to DNA fragments. The PCR was made with a primer terminated with the AGCTT adapter sequence (PowaAGCT 5'-CTCA CTCTCACCAACGTCGACAGCTT-3'). Electrophoresis of all PCR products was carried out in 3\% agarose gels. T. mentagrophytes CBS570.80 and CBS677.86 were used as the reference strains. All analyses were made in triplicate.

\section{Evaluation of production of virulence factors}

The production of virulence factors was evaluated using specific test media. The following tests were performed: production of keratinase (1), elastase (2), phospholipase (3), lipase (4), protease (5), gelatinase (6), and detection of haemolytic activity (7). Keratinase production (1): the medium was prepared as described by Scott and Untereiner [38]. The basal layer containing $0.5 \mathrm{~g} / 1 \mathrm{MgSO}_{4} \cdot 7 \mathrm{H}_{2} \mathrm{O}, 0.05 \mathrm{~g} / \mathrm{KCl}, 0.5 \mathrm{~g} / 1$ $\mathrm{K}_{2} \mathrm{HPO}_{4}, 0.1 \mathrm{~g} / 1 \mathrm{ZnSO}{ }_{4} \cdot 7 \mathrm{H}_{2} \mathrm{O}, 0.1 \mathrm{~g} / 1 \mathrm{FeSO}_{4} \cdot 7 \mathrm{H}_{2} \mathrm{O}, 0.03 \mathrm{~g} / 1$ 
Fig. 1 Micro- and macroscopic morphology of Trichophyton mentagrophytes strains after 14 days of incubation. Notes: Colonies flat, white in colour, with a powdery surface. The size of the colony in the range from 10 to $15 \mathrm{~mm}$. The edges of the colony are smooth with a slight furrow in the form of a star. Image from Sabouraud medium (a) and from DTM (dermatophyte test medium) (b). Numerous singlecelled microconidia are formed, often in dense clusters. The micromorphological image (taken with a fluorescence microscope Olympus BX51) on the microscope slide stained with calcofluor white revealed numerous hyaline, smoothwalled, and spherical microconidia placed laterally on hyphae (c, magnification $\times 400$ ). The multicelled, cigar-shaped macroconidia are sporadic (d, magnification $\times 1000$ )
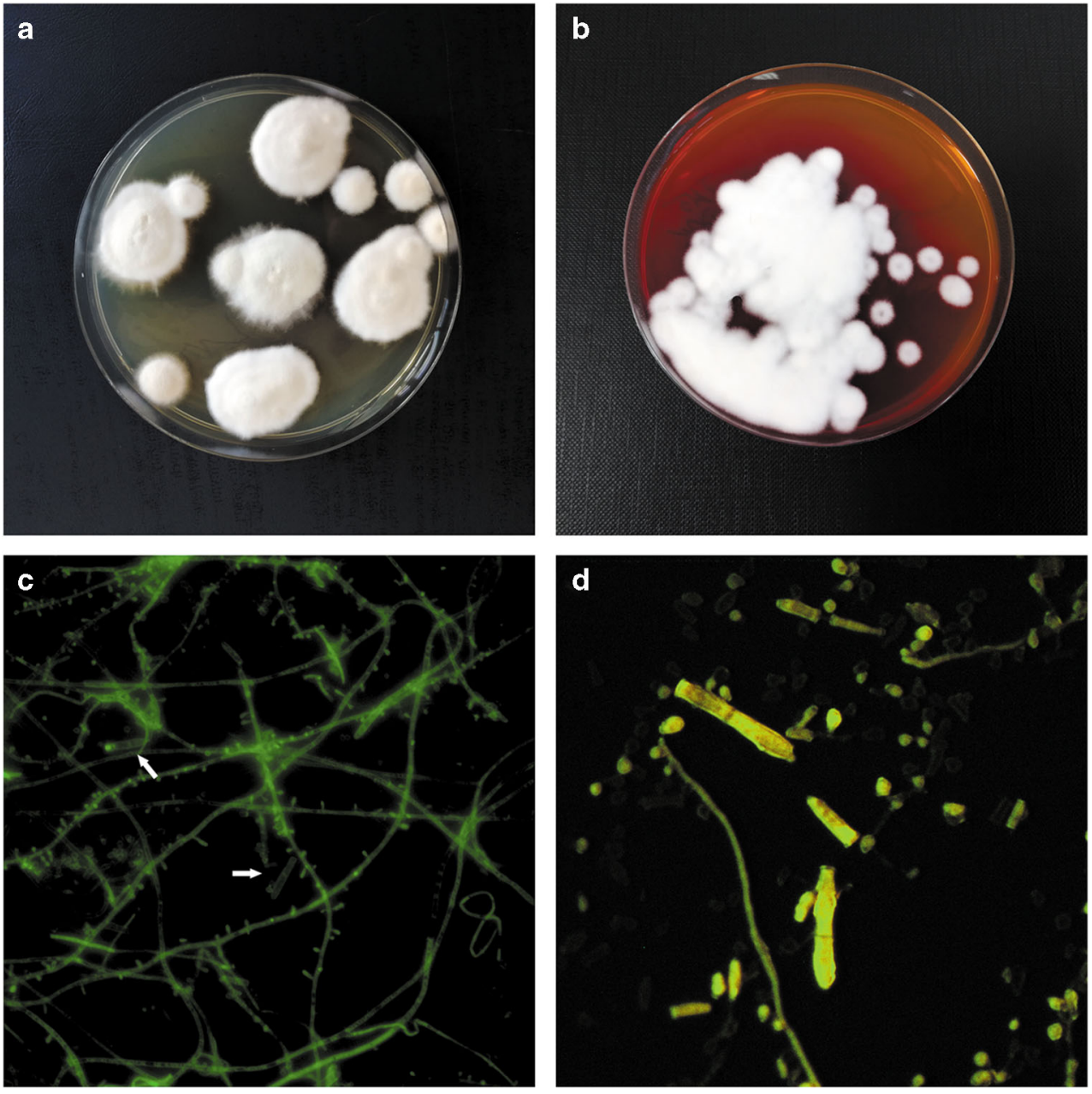

$\mathrm{CuSO}_{4}$, and $25.0 \mathrm{~g} / \mathrm{l}$ agar was dispensed horizontally in sterilized test tubes. The upper layer was supplemented with $4 \mathrm{mg} / \mathrm{ml}$ keratin azure. Clinical isolates inoculated with the medium grew for 1 month in the dark at $37^{\circ} \mathrm{C}$. A change of the colour of the basal layer from milky white to blue was a positive result. Chrysosporium keratinophilum CBS104.62 was used as a positive control. The elastin activity (2) was determined on two-layer plates as described by Rippon and Varadi [39]. The basal layer containing $8.0 \mathrm{~g} / \mathrm{l}$ nutrient broth and $20.0 \mathrm{~g} / \mathrm{l}$ Agar Noble was poured in a thin layer onto Petri dishes; the upper layer was supplemented with $3.4 \mathrm{~g} / 1$ elastin from bovine neck ligament. Brighter zones around the colonies after incubation at $37{ }^{\circ} \mathrm{C}$ for 14 days indicated elastinase activity. Pseudomonas aeruginosa ATCC15152 was used as a positive control. The phospholipase assay (3) was performed according to the method described by Gnat et al. [40]. Briefly, the medium containing (g/l) $10.0 \mathrm{~g} / 1$ peptone, $20.0 \mathrm{~g} / 1 \mathrm{dex}-$ trose, $57.3 \mathrm{~g} / 1 \mathrm{NaCl}, 0.005 \mathrm{~g} / 1 \mathrm{CaCl}_{2}, 20.0 \mathrm{~g} / \mathrm{l}$ agar, and $50 \mathrm{ml}$ egg yolk was punctiform inoculated with a single dermatophyte colony in the centre of the plate and incubated for 14 days at $28^{\circ} \mathrm{C}$. A clear halo zone around the colony indicated phospholipase production. Candida albicans
ATCC10231 was used as a positive control. The lipase activity (4) was tested on medium containing $10.0 \mathrm{~g} / 1$ peptone, $5.0 \mathrm{~g} / 1 \mathrm{NaCl}, 0.1 \mathrm{~g} / 1 \mathrm{CaCl}_{2}, 20.0 \mathrm{~g} / \mathrm{l}$ agar, and $10 \mathrm{ml}$ Tween 80 as described by Muhsin et al. [41]. Isolates of dermatophytes were punctiform inoculated in the centre of the plate and incubated for 14 days at $28^{\circ} \mathrm{C}$. A clear halo zone of precipitation around the colony indicated lipase production. Malassezia furfur ATCC14521 was used as a positive control. Protease activity (5) was tested on casein medium with bromocresol green (BCG) as described by Vijayaraghavan et al. [42]. The medium containing $5.0 \mathrm{~g} / 1$ meat peptone $1.5 \mathrm{~g} / \mathrm{l}$ beef extract, $1.5 \mathrm{~g} / 1$ yeast extract, $5.0 \mathrm{~g} / 1 \mathrm{NaCl}$, agar, $15,10.0 \mathrm{~g} / \mathrm{l}$ casein, $0.0015 \%$ (w/v) BCG, and $15.0 \mathrm{~g} / \mathrm{l}$ agar was punctiform inoculated in the centre of the plate and incubated for 14 days at $28^{\circ} \mathrm{C}$. A zone of proteolysis around the colony was a positive result. Bacillus subtilis ATCC6633 was used as a control. The gelatinase assay (6) was performed according to the method described by Gnat et al. [40]. The medium containing $5.0 \mathrm{~g} / 1$ neopeptone, $3.0 \mathrm{~g} / 1$ beef extract, and $120.0 \mathrm{~g} / 1$ gelatin was poured into tubes, inoculated, and incubated at $25{ }^{\circ} \mathrm{C}$ for a month. After this period, all tubes were cooled to $4{ }^{\circ} \mathrm{C}$ and tilted to check if the gelatin was liquefied. The 
Table 1 Samples tested and isolates of Trichophyton mentagrophytes obtained from animals and humans with a description

\begin{tabular}{|c|c|c|c|c|c|c|c|c|}
\hline \multirow[t]{2}{*}{ Isolates } & \multirow[t]{2}{*}{ Host } & \multirow[t]{2}{*}{ Isolation source } & \multirow[t]{2}{*}{ Oral treatment } & \multirow[t]{2}{*}{ Topical treatment } & \multirow[t]{2}{*}{ Duration (days) } & \multicolumn{2}{|c|}{ Real-time PCR identification } & \multirow[t]{2}{*}{ Culture } \\
\hline & & & & & & $\begin{array}{l}\text { Pan- } \\
\text { dermatophyte }\end{array}$ & $\begin{array}{l}\text { Species- } \\
\text { specific }\end{array}$ & \\
\hline TMH1/20 & Human & Tinea capitis & Terbinafine & Ciclopirox & 32 & + & + & + \\
\hline TMH $2 / 20$ & Human & Tinea capitis & Terbinafine & Ketoconazole & 28 & + & - & - \\
\hline TMH3/20 & Human & Tinea capitis & Terbinafine & Ketoconazole & 34 & + & + & + \\
\hline TMH4/20 & Human & Tinea capitis & Terbinafine & Ketoconazole & 34 & + & + & + \\
\hline TMH5/20 & Human & Tinea capitis & Ketoconazole & Naftifine & 30 & + & - & - \\
\hline TMH6/20 & Human & Tinea corporis & Ketoconazole & Ciclopirox & 28 & + & - & - \\
\hline TMH7/20 & Human & Tinea unguium & Fluconazole & Amorolfine & 44 & + & + & + \\
\hline TMH8/20 & Human & Tinea capitis & Terbinafine & Ciclopirox & 28 & + & + & + \\
\hline TMH9/20 & Human & Tinea corporis & Itraconazole & Ciclopirox & 29 & + & + & + \\
\hline TMH10/20 & Human & Tinea corporis & Itraconazole & Ciclopirox & 28 & + & + & + \\
\hline TMH1/19 & Human & Tinea capitis & Ketoconazole & Terbinafine & 36 & + & + & + \\
\hline TMH2/19 & Human & Tinea capitis & Terbinafine & Ketoconazole & 29 & + & + & - \\
\hline ТМH3/19 & Human & Tinea corporis & Itraconazole & Ciclopirox & 38 & + & + & + \\
\hline TMH4/19 & Human & Tinea unguium & Fluconazole & Amorolfine & 51 & + & + & + \\
\hline TMH5/19 & Human & Tinea capitis & Terbinafine & Ciclopirox & 37 & + & + & + \\
\hline TMH6/19 & Human & Tinea capitis & Terbinafine & Ketoconazole & 28 & + & + & + \\
\hline ТМH7/19 & Human & Tinea capitis & Terbinafine & Ketoconazole & 28 & + & + & + \\
\hline TMH8/19 & Human & Tinea corporis & Itraconazole & Naftifine & 29 & + & + & - \\
\hline TMH9/19 & Human & Tinea corporis & Itraconazole & Naftifine & 32 & + & - & - \\
\hline TMH10/19 & Human & Tinea capitis & Ketoconazole & Naftifine & 28 & + & + & + \\
\hline TMH11/19 & Human & Tinea capitis & Ketoconazole & Naftifine & 28 & + & + & + \\
\hline TMH12/19 & Human & Tinea capitis & Terbinafine & Ciclopirox & 36 & + & + & + \\
\hline TMH13/19 & Human & Tinea capitis & Terbinafine & Ketoconazole & 41 & + & + & + \\
\hline TMH14/19 & Human & Tinea corporis & Itraconazole & Terbinafine & 36 & + & - & - \\
\hline TMA1/20 & Fox & Head & - & Enilconazole & 37 & + & - & - \\
\hline TMA2/20 & Fox & Head & - & Enilconazole & 37 & + & - & - \\
\hline TMA3/20 & Fox & Head, neck & - & Enilconazole & 37 & + & + & + \\
\hline TMA4/20 & Fox & Neck & - & Enilconazole & 45 & + & + & + \\
\hline TMA5/20 & Fox & Torso & - & Enilconazole & 45 & + & + & + \\
\hline TMA6/20 & Fox & Multiple & - & Enilconazole & 28 & + & + & + \\
\hline TMA7/20 & Fox & Multiple & - & Enilconazole & 28 & + & + & + \\
\hline TMA8/20 & Fox & Head & - & Enilconazole & 28 & + & + & + \\
\hline TMA9/20 & Fox & Neck & - & Enilconazole & 28 & + & + & + \\
\hline TMA10/20 & Fox & Torso & - & Enilconazole & 28 & + & + & + \\
\hline TMA11/20 & Guinea pig & Head & Terbinafine & Miconazole & 31 & + & - & - \\
\hline TMA12/20 & Guinea pig & Head, neck & Terbinafine & Miconazole & 29 & + & + & - \\
\hline TMA13/20 & Guinea pig & Torso & Itraconazole & - & 37 & + & + & + \\
\hline TMA14/20 & Guinea pig & Multiple & Griseofulvin & Lime sulphur & 46 & + & + & + \\
\hline TMA15/20 & Guinea pig & Multiple & Griseofulvin & Lime sulphur & 46 & + & + & + \\
\hline TMA16/20 & Guinea pig & Multiple & Itraconazole & - & 32 & + & + & + \\
\hline TMA1/19 & Rabbit & Head & Itraconazole & - & 32 & + & + & + \\
\hline TMA2/19 & Rabbit & Torso & Itraconazole & - & 32 & + & - & - \\
\hline TMA3/19 & Fox & Head & - & Enilconazole & 49 & + & - & - \\
\hline TMA4/19 & Fox & Multiple & - & Enilconazole & 49 & + & + & + \\
\hline TMA5/19 & Fox & Torso & - & Enilconazole & 28 & + & + & + \\
\hline TMA6/19 & Guinea pig & Head & Itraconazole & Miconazole & 44 & + & + & + \\
\hline
\end{tabular}


Table 1 (continued)

\begin{tabular}{|c|c|c|c|c|c|c|c|c|}
\hline \multirow[t]{2}{*}{ Isolates } & \multirow[t]{2}{*}{ Host } & \multirow[t]{2}{*}{ Isolation source } & \multirow[t]{2}{*}{ Oral treatment } & \multirow[t]{2}{*}{ Topical treatment } & \multirow[t]{2}{*}{ Duration (days) } & \multicolumn{2}{|c|}{ Real-time PCR identification } & \multirow[t]{2}{*}{ Cultur } \\
\hline & & & & & & $\begin{array}{l}\text { Pan- } \\
\text { dermatophyte }\end{array}$ & $\begin{array}{l}\text { Species- } \\
\text { specific }\end{array}$ & \\
\hline TMA7/19 & Guinea pig & Neck & Itraconazole & Miconazole & 34 & + & + & + \\
\hline TMA8/19 & Fox & Torso & - & Enilconazole & 58 & + & + & + \\
\hline TMA9/19 & Cat & Head, neck & Itraconazole & -* & 28 & + & + & + \\
\hline TMA10/19 & Cat & Torso & Itraconazole & $-*$ & 28 & + & + & + \\
\hline TMA11/19 & Dog & Head & Itraconazole & $-*$ & 28 & + & - & - \\
\hline TMA12/19 & Dog & Neck & Itraconazole & -* $^{*}$ & 33 & + & + & + \\
\hline TMA13/19 & Dog & Multiple & Griseofulvin & Miconazole & 45 & + & + & + \\
\hline TMA14/19 & Fox & Head, neck & - & Enilconazole & 26 & + & + & + \\
\hline TMA15/19 & Fox & Torso & - & Enilconazole & 31 & + & + & + \\
\hline TMA16/19 & Guinea pig & Multiple & Griseofulvin & Lime sulphur & 46 & + & + & + \\
\hline TMA17/19 & Rabbit & Head & Terbinafine & Miconazole & 29 & + & - & - \\
\hline TMA18/19 & Rabbit & Head, neck & Terbinafine & Miconazole & 28 & + & + & + \\
\hline TMA19/19 & Rabbit & Multiple & Griseofulvin & Lime sulphur & 42 & + & + & + \\
\hline
\end{tabular}

*Vaccine used instead of topical treatment

gelatinase secretion was determined on the basis of the physical state of the medium: liquid medium was a positive result. Staphylococcus aureus ATCC29213 was used as a positive control. The haemolytic activity (7) was assessed using Columbia agar medium (BioMaxima, Lublin, Poland) supplemented with $5 \%$ defibrated sheep blood as described by Schaufuss et al. [43]. A needle was used for punctiform inoculation with a single colony, and then incubation at $28{ }^{\circ} \mathrm{C}$ lasted for 7 days. The presence of a translucent halo around the colony was a positive result. Staphylococcus aureus ATCC25923 was used as a positive control for $\beta$-haemolysis, Streptococcus pneumoniae ATCC6305 for $\alpha$-haemolysis, and Clostridium perfringens ACTCC13124 for double zone haemolysis. The catalase activity was determined on medium containing $3 \%$ hydrogen peroxide and $2 \%$ agar. Wells cut out on a Petri dish were supplemented with the dermatophyte suspension. The plates were incubated at $28{ }^{\circ} \mathrm{C}$ for $6 \mathrm{~h}$ aseptically. The staining solution containing $2 \%$ of $\mathrm{K}_{3} \mathrm{Fe}(\mathrm{CN})_{6}$ and $\mathrm{FeCl}_{3} \cdot 6 \mathrm{H}_{2} \mathrm{O}$ each was prepared ex tempore. The staining solution was poured into Petri dishes containing the samples, which were then shaken gradually until a green colour appeared. The staining solution was then filtered off, and the plate was rinsed and filled with distilled water. The appearance of a yellow ring around the well was considered a positive result. Staphylococcus aureus ATCC6538 was used as a positive control. For each test, the clinical isolates of the dermatophytes were incubated on MM-Cove medium with keratin azure (Sigma-Aldrich, Missouri, USA) for 14 days at $28^{\circ} \mathrm{C}$. Unless otherwise described, a halo zone diameter exceeding $50 \%$ of the dermatophyte colony diameter was regarded as a positive result. Each test was made in triplicate.

\section{Determining the host range of isolates}

The host range of the dermatophytes was determined with the method described previously by Gnat et al. [44]. The basis for the determination was the diverse keratinolytic activity against species-specific keratin substrates. Cultures used for this test were inoculated onto liquid Sabouraud glucose agar (BioMaxima, Lublin, Poland) at $37^{\circ} \mathrm{C}$ for 15 days with shaking at $110 \mathrm{rpm}$ (Multitron, Infors, Switzerland). Next, the mycelium was collected and mechanically homogenized, resuspended to a concentration of 1 in McFarland, and used as the source of enzymes. Hairs and fur obtained from Bos taurus (cow), Canis familiaris (dog), Cavia porcellus (guinea pig), Equus caballus (horse), Felis catus (cat), Homo sapiens (human), Ovis aries (sheep), Sus domesticus (pig), and Vulpes vulpes (fox) during routine hygiene operations were cut separately into 1-mm pieces, washed, and defatted. After drying, they were used as substrates. Keratin azure (Sigma-Aldrich, Missouri, USA) was used as a positive control and indicator substrate. The substrates and sources of the enzyme were added to a liquid minimal medium (MM-Cove) designed to determine keratinolytic activity at a concentration of $0.06 \%$ and in a volume $100 \mu$ l, respectively. The enzymatic activity $\left(\mathrm{Uh}^{-1}\right)$ was determined spectrophotometrically at a wavelength of $550 \mathrm{~nm}$ (SmartSpec, BioRad, USA) as mycelium growth per hour of incubation on incubation days $4,7,10$, 15,30 , and 60 . The test was performed in three replicates simultaneously, and differences between enzymatic activity in different periods of analysis as well as various substrates were assessed by Student's $t$ test using the R program version 3.6.3 (R Core Team, Missouri, USA). 


\section{Antifungal susceptibility tests}

In vitro testing of the susceptibility to allylamine, polyene, imidazole, triazole, and pyridinone derivatives as well as phenyl morpholine derivatives was performed according to the Clinical and Laboratory Standards Institute (CLSI) document M38-A3 (CLSI, 2018). Reagent-grade amorolfine (AMR), amphotericin $\mathrm{B}$ (AMB), ciclopirox (CPO), enilconazole (ENC), fluconazole (FLC), griseofulvin (GRE), itraconazole (ITC), ketoconazole (KTC), miconazole (MCZ), naftifine (NFT), terbinafine (TRB), and voriconazole (VRC) were obtained in the powder form (Sigma-Aldrich, Missouri, USA). Drug stock solutions were prepared in dimethyl sulfoxide (DMSO) to reach the final DMSO concentration in the wells below $1 \%$. The drugs were analysed at the final concentration in the range of 0.002 $2 \mu \mathrm{g} / \mathrm{ml}$ for allylamine, pyridinone derivatives, and phenyl morpholine derivatives, $0.004-4 \mu \mathrm{g} / \mathrm{ml}$ for polyenes, imidazoles, itraconazole, and voriconazole, and $0.06-64 \mu \mathrm{g} / \mathrm{ml}$ for fluconazole. The dermatophyte isolates were cultured on Sabouraud glucose agar (BioMaxima, Lublin, Poland) for 21 days, and conidial suspensions were prepared by gentle scraping mature colonies into sterile physiological saline containing $0.002 \%$ Tween 80 . Homogeneous inoculum supernatants were collected, and their optical density (OD) at $530 \mathrm{~nm}$ was adjusted spectrophotometrically to an OD of 0.11 to 0.13 , which ranged from 65 to $70 \%$ transmission, and the final density of inoculum was $1 \times 10^{3}$ to $3 \times 10^{3} \mathrm{CFU} / \mathrm{ml}$. The inocula were diluted 1:50 in RPMI 1640 medium and incubated with the indicated concentrations of the antifungals in 96-well plates at $35^{\circ} \mathrm{C}$ for $72 \mathrm{~h}$. Minimum inhibitory concentrations (MICs) were determined visually using a reading mirror as complete inhibition of observable growth. Trichophyton mentagrophytes ATCC4439 and T. rubrum ATCC4438 served as quality controls for every new series of MIC plates. All tests were performed in triplicate, and differences between mean values were assessed by Student's $t$ test using the R program version 3.6.3 (R Core Team, Missouri, USA).

\section{Results}

\section{Genetic diversity of dermatophyte isolates}

In this study, the dermatophytes isolated from human and animal infections in Poland were characterized for genomic diversity and relationships with the commonly used DNA fingerprinting technique based on PCR reaction, i.e. MPPCR. Six genotypes of the 17 human isolates of T. mentagrophytes were distinguished (Fig. 2). In turn, nine genotypes were identified in the animal isolates. In each case, similar genomic diversity values of $35.3 \%$ and $33.3 \%$ were obtained for the clinical isolates from humans and animals, respectively. No relationship was demonstrated between the antifungal drug resistance profile and the MP-PCR profile. In addition, no relationship between the profile and the host species was found for the animal isolates. There were no profiles specific for human or animal isolates either, but specific electrophoretic patterns appeared in T. mentagrophytes isolated from both types of cases.

\section{Production of virulence factors and the host range of isolates}

The enzyme profiles obtained for the human and animal isolates were not significantly differentiated (Table 2). All the tested clinical isolates of T. mentagrophytes showed keratinase, phospholipase, protease, and catalase enzymatic activity as well as haemolytic activity (Fig. 3). In turn, extracellular elastase was produced only by the clinical isolates obtained from humans, and lipase was produced by the animal isolates. Furthermore, no strains diverging from the relationship were found: when the enzymatic activity was positive, it was exhibited by $100 \%$ of the tested isolates, as in the case of negative results.

Particularly important is the species-specific keratinolytic activity, which is recognized as a determinant of the host range

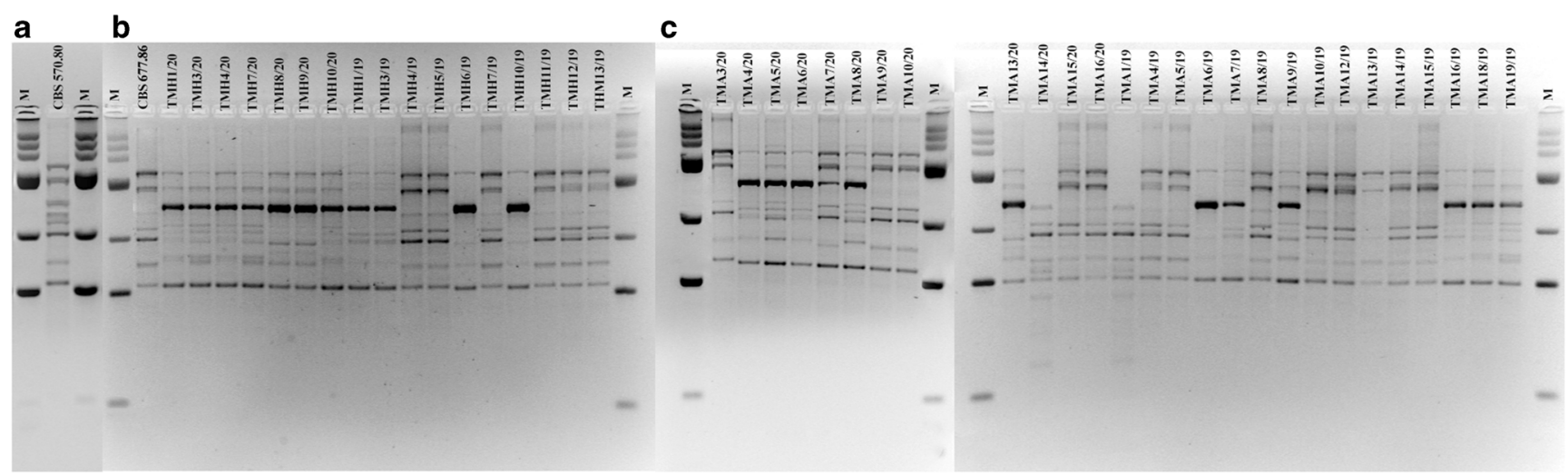

Fig. 2 Electrophoretic profile obtained by Melting Profile (MP-PCR) in 3\% agarose gel. Notes: a reference strain Trichophyton mentagrophytes CBS570.80, b reference strain Trichophyton mentagrophytes complex
CBS677.86 and isolates from humans, $\mathbf{c}$ isolates from animals. In the first line $\mathrm{M}$ - molecular weight marker GeneRuler ${ }^{\mathrm{TM}} 100$ bp DNA Ladder Plus (100-3000 bp; Thermo Fisher, Waltham, USA) 
Table 2 Enzymatic activity in vitro of Trichophyton mentagrophytes isolates obtained from humans and animals

\begin{tabular}{llllllll}
\hline Isolates & Keratinase & Phospholipase & Lipase & Protease & Elastase & Haemolysis \\
\hline Humans & + & + & - & + & + & + & + \\
Animals & + & + & + & + & - & + & + \\
\hline
\end{tabular}

of dermatophytes. The degree of keratinolytic activity ranged from $0.8 \mathrm{Uh}^{-1}$ and $1.0 \mathrm{Uh}^{-1}$ on day 4 of incubation to $5.4 \mathrm{Uh}^{-1}$ on day 30 of incubation and $5.8 \mathrm{Uh}^{-1}$ on day 15 of incubation for the T. mentagrophytes clinical isolates from humans and animals, respectively (Fig. 4). The highest activity of keratinase enzymes of the tested isolates was recorded in media containing keratin from the fox (Vulpes vulpes), guinea pig (Cavia porcellus), and human (Homo sapiens) hairs. In these three cases, the degree of keratinolytic activity was statistically significantly higher $(p<0.05)$ than in the medium with keratin azure; it was $5.8 \mathrm{Uh}^{-1}, 5.7 \mathrm{Uh}^{-1}$, and $4.9 \mathrm{Uh}^{-1}$ for the fox, human, and guinea pig hairs on day 15 of incubation for the animal isolates, and $5.2 \mathrm{Uh}^{-1}, 4.95 \mathrm{Uh}^{-1}$, and $4.6 \mathrm{Uh}^{-1}$ for the human isolates, respectively. In turn, this value for keratin azure was $2.05 \mathrm{Uh}^{-1}$. Additionally, the geometric mean of

Fig. 3 In vitro enzymatic activity of Trichophyton mentagrophytes strains obtained from human and animals cases. Notes: a haemolytic activity; $\mathbf{b}-$ keratinase activity; $\mathbf{c}$ - gelatinase activity; $\mathbf{d}$ - elastase activity; $\mathbf{e}, \mathbf{f}-$ lipase activity; g; g' - catalase activity; $\mathbf{h}, \mathbf{i}$ - phospholipase activity

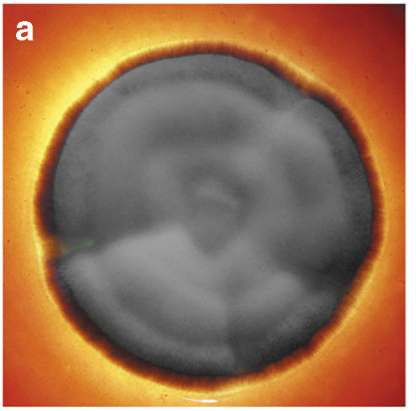

keratinolytic activity on day 15 of incubation for three most active species was statistically significantly higher than for all the other species-specific hairs, i.e. $5.46 \mathrm{Uh}^{-1}$ vs. $3.13 \mathrm{Uh}^{-1}$ and $4.92 \mathrm{Uh}^{-1}$ vs. $2.98 \mathrm{Uh}^{-1}$ for the animal and human isolates, respectively. Interestingly, the animal T. mentagrophytes isolates exhibited higher keratinolytic activity against human hairs than all the others on day 30 of incubation. On the contrary, this relationship was not revealed for the human isolates, where the keratinolytic activity was at the highest level for the fox keratin in all periods.

\section{Antifungal susceptibility tests}

The sensitivity to the antifungal substances was similar in the clinical isolates of T. mentagrophytes obtained from
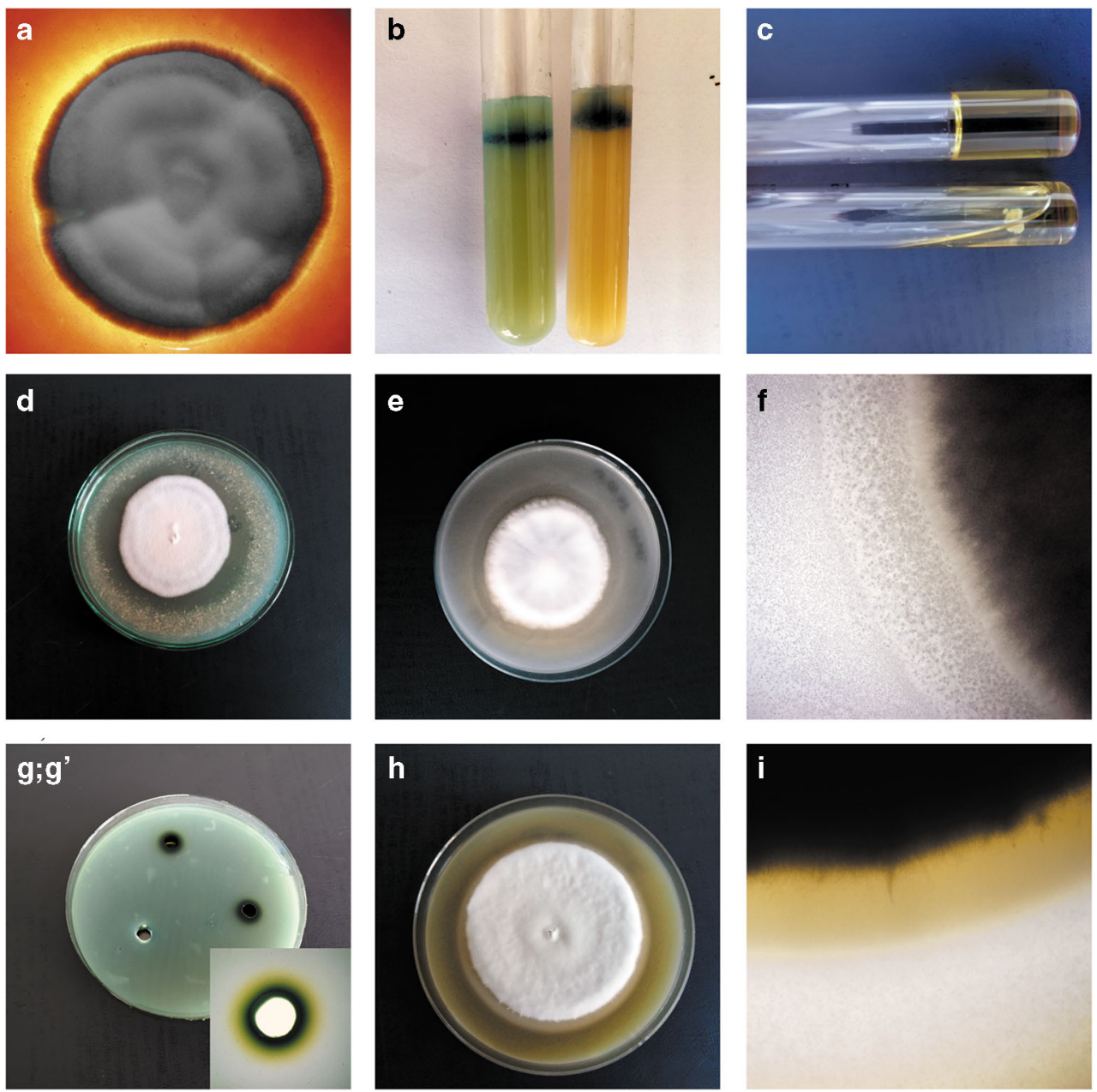
Trichophyton mentagrophytes - animal isolates MM-Cove

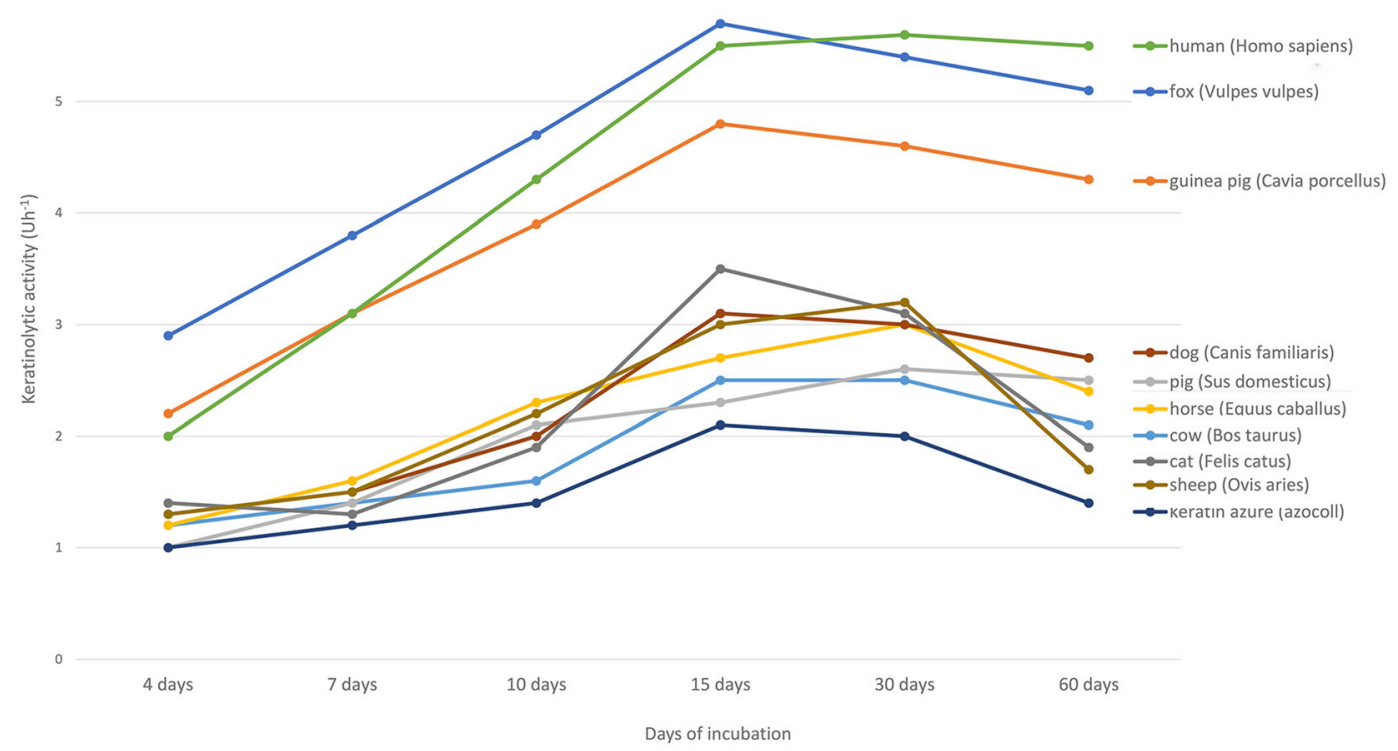

Trichophyton mentagrophytes - human isolates MM-Cove

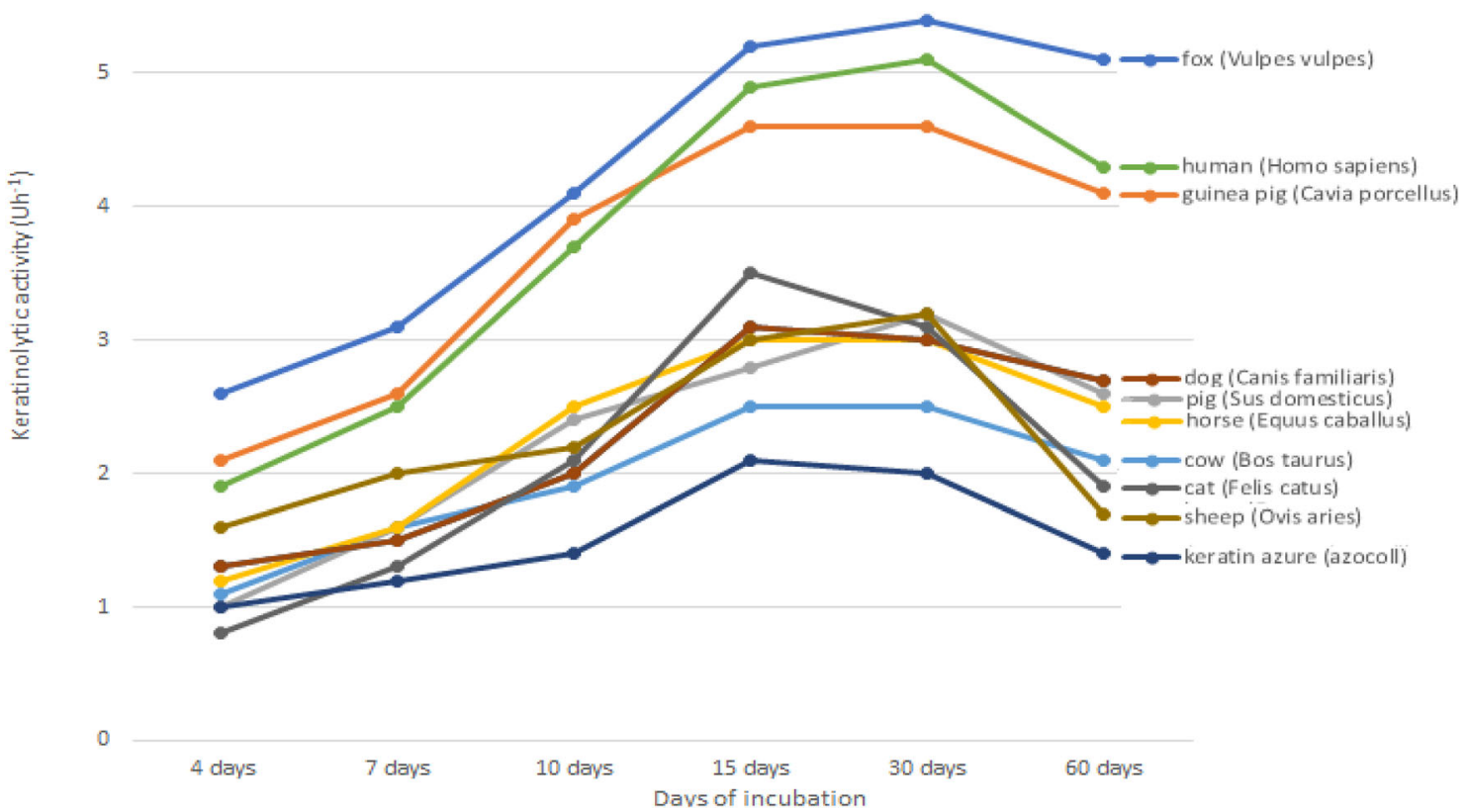

Fig. 4 Graph of changes in keratinolytic activity $\left(\mathrm{Uh}^{-1}\right)$ in various incubation periods on MM-Cove medium supplemented with species-specific types of keratins and keratin azure for the Trichophyton mentagrophytes clinical isolates

humans and animals. The MIC ranges, geometric means of MICs, $\mathrm{MIC}_{50}, \mathrm{MIC}_{90}$, and mode ratios of the 12 antifungal drugs used are summarized in Table 3. Phenyl morpholine derivatives, i.e. amorolfine, exhibited superior activity against strains obtained from both humans and animals with the lowest $\mathrm{MIC}_{50}$ values. In turn, griseofulvin was found to exert the weakest in vitro effect and had the highest $\mathrm{MIC}_{50}$ values in the tested isolates. Additionally, fluconazole had the widest MIC range, i.e. $0.06-32 \mu \mathrm{g} / \mathrm{ml}$ for the human isolates and $0.125-32 \mu \mathrm{g} / \mathrm{ml}$ for the animal isolates, respectively. Remarkably, $\mathrm{MIC}_{90}$ values above $1 \mu \mathrm{g} / \mathrm{ml}$ were obtained for grisofulvin, enilconazole, ketoconazole, and fluconazole in both groups of the tested strains and for terbinafine and itraconazole in the case of the human 


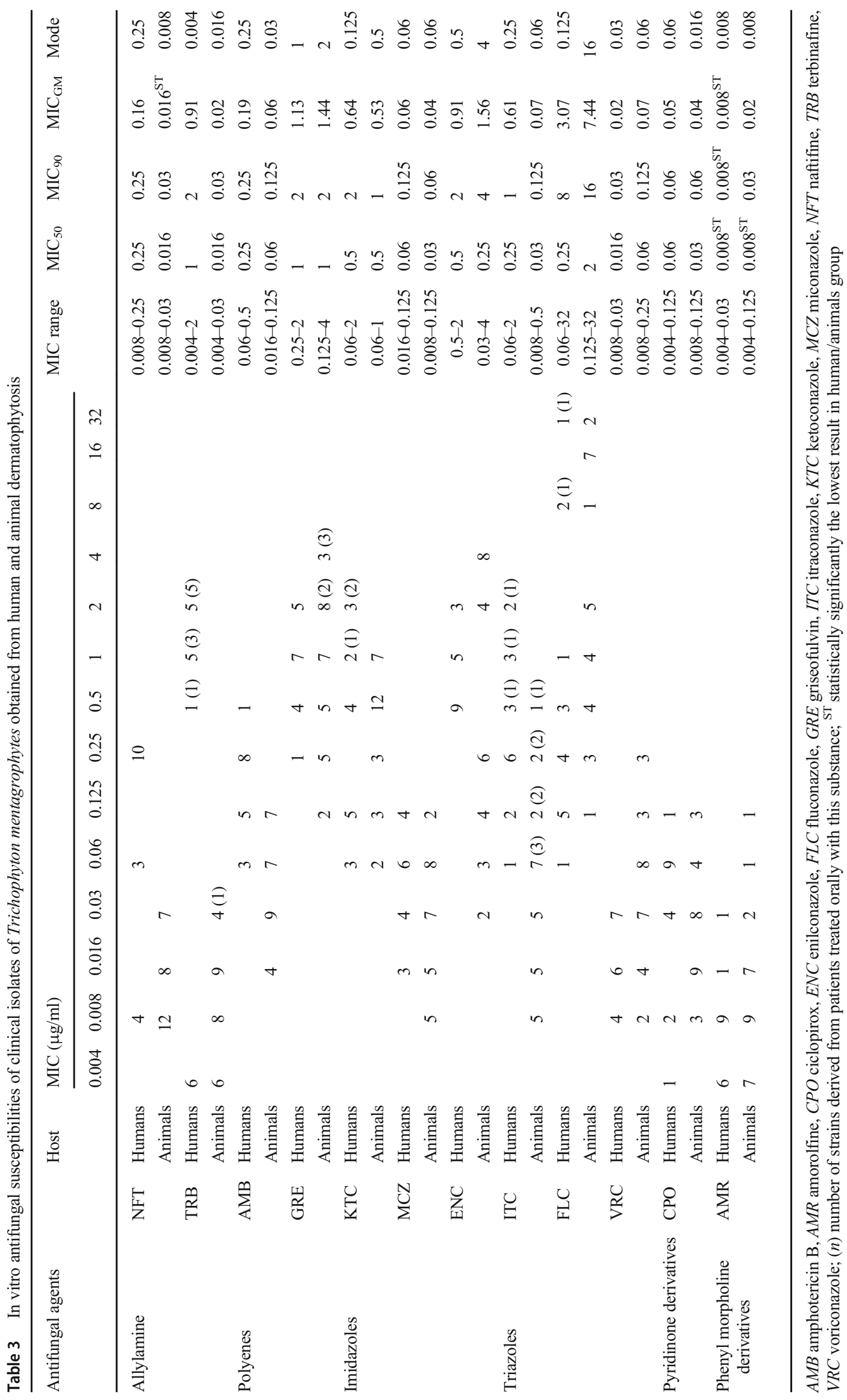


T. mentagrophytes isolates. Interestingly, the lowest statistically significant geometric mean of the MIC values $(p<0.05)$ for the dermatophytes isolated from humans were noted for amorolfine. Furthermore, the lowest geometric mean MIC value (without statistical significance) was obtained for naftifine in the case of the animal isolates.

\section{Discussion}

Given the growing prevalence of superficial dermatophyte infections, especially in immunocompromised patients, these diseases are regarded as a public health issue worldwide [8]. The immune status of the host has been referred to as the main factor determining the outcome of the courses of the disease, which may range from limited cutaneous or subcutaneous infections to invasive disseminated life-threatening symptoms [45]. Despite their availability, the arsenal of antifungal drugs for clinical use acts on a limited number of cellular targets [46]. Moreover, the overlapping mechanisms of action of the commonly used drugs may contribute to emergence of multidrug resistance (MDR) phenotypes observed for several pathogenic fungi [47]. Additionally, it is common for a large group of patients and animal breeders to neglect and abandon treatment due to its cost, duration, and many side effects [48]. In this study, we present the characteristics of $T$. mentagrophytes dermatophytes obtained from patients and animals undergoing antifungal therapy (Table 1). Among the positive tests in 24 patients and 35 animals of different species selected by the real-time PCR technique, dermatophyte cultures were obtained in 17 and 27 cases, respectively. This represents a very high percentage ( $70.8 \%$ and $77.1 \%$ ), indicating that living elements of the fungus are still present in the affected areas despite the treatment.

Molecular typing methods can provide crucial insights into the epidemiology and pathogenicity of dermatophytes [49, 50]. These techniques can also help to characterize infecting strains and monitor their occurrence and distribution [31]. Moreover, the most important investigation in the molecular epidemiology of dermatophytes is to determine whether infections are caused by the same or different strains [51]. In this aspect, disclosure of infection sources and transmission pathways in populations of humans and animals is necessary, and available techniques should allow deep genetic differentiation of strains within species, thus facilitating prompt and reliable identification of individual clones [52]. Our investigation showed a relatively high genomic diversity revealed by the MP-PCR analysis of clinical isolates of T. mentagrophytes of both human and animal origin. Although the MP-PCR method is widely described in the literature as a useful tool for the epidemiological analysis of the source of infection [31, 49, $51,53]$, it seems that it cannot be used to detect recalcitrant to treatment dermatophyte isolates. The molecular basis of terbinafine resistance is most widely described to result mostly from changes at the genome level $[18,27,54,55]$. However, in our study, out of 8 strains with in vitro resistance to this drug (MIC $\geq 1 \mu \mathrm{g} / \mathrm{ml}$ ) obtained from patients treated with this substance, 4 different electrophoretic MP-PCR profiles were revealed. Thus, it is probably not possible to indicate one MPPCR profile for T. mentagrophytes isolates exhibiting terbinafine resistance. There are no similar results in the literature and therefore this aspect requires more extensive analysis.

Despite the superficial localization of dermatophyte colonization, the host-fungus relationship in these infections is complex and not fully elucidated $[22,56]$. Additionally, the pathophysiological mechanism is strictly correlated with the dermatophyte species, the host, and their immune status [57, 58]. Remarkably, the pattern of enzymes secreted by dermatophytes may underlie their survival in the host stratum corneum and, consequently, in the clinical pictures of the infection, not only by providing nutrients to the detriment of the keratinized barrier, but also by triggering and modulating the immune response $[26,40,59]$. The knowledge about the range of enzymes produced by dermatophytes with functions in pathogenesis is constantly growing; however, it is still not entirely clear whether the enzyme profile is the most important factor in the severity of symptoms $[22,60]$. The data presented in this article show that dermatophytes isolated from animals and humans with skin lesions are able to produce different enzymes in vitro. However, it is difficult to capture the clear host-related relationship and the enzyme that causes recalcitrance to treatment. All analysed isolates produced keratinases, which are used by most dermatophytes to establish infection on hosts [44, 49]. However, as suggested by Mignon et al. [61] and Cafarchia et al. [62], it seems that keratinase activity is not associated with the presence of cutaneous lesions or any particular clinical picture of dermatophytosis. In contrast, the level of the activity of this enzyme might be correlated with the symptomatic infections of animals and humans, as shown in our research.

Furthermore, a distinct tendency indicating the highest keratinolytic activity of the T. mentagrophytes strains in the 15-30-day incubation period was revealed in our study. Wawrzkiewicz et al. [63] suggest that the keratinolytic activity of dermatophyte strains is connected with the fungal cell, and the enzyme is produced extracellularly only in the case of $T$. verrucosum strains. Thus, keratinolytic activity can be directly linked to the presence of dermatophyte mycelium, and its increase is associated with stronger pathogenicity [47, 64]. Additionally, another issue is the induction of the activity with a suitable substrate rather than the amount of enzyme protein in the culture $[44,65]$. Our results indicate that the activity of T. mentagrophytes keratinase is induced by the substrate and the host range can be clearly determined (Fig. 4). This finding is in agreement with a study conducted by Mercer et al. [66]. 
The researchers conclude that the accumulation of keratinase does not correlate positively with higher intensity of natural keratin degradation, and the predisposition of enzymes resulting from the adaptation of the fungus to the natural host may play a key role. This dependence is noticeable in our studies. The clinical isolates of T. mentagrophytes showed higher in vitro keratinolytic activity against the fox, guinea pig, and human hairs than against the other ones. Initially, these observations were considered to indicate a source of fungal infection in humans, which was related to the high keratinolytic activity only for species-specific types of substrate $[32,67,68]$. Contrarily, the range of dermatophyte hosts can be closely correlated with the similar structure of keratin in the hair of these species [44, 69]. Final conclusions require more extensive research.

In the last decades, various new antifungal drugs with increased efficacy and an associated anti-inflammatory effect have been introduced and have broadened the munition against dermatophytosis $[11,70]$. However, the treatment of this disease is still less successful than that of bacterial infections, especially because fungal cells are eukaryotic and much more similar to human and animal cells than bacteria [2]. Furthermore, recalcitrant dermatophyte infections may be related to inadequate or discontinued treatment, difficulties in eliminating predisposing factors in hosts or infection sources, and re-infections [17, 22, 49, 71]. According to experts, the minimum duration of therapy in recalcitrant cases of dermatophytoses should be 4 weeks [72]. However, there is no single official position of dermatologists on this subject and individual studies differ in interpretations. Nonetheless, recalcitrant or recurrent infections after completion of a recommended therapy or antifungal drug-resistant dermatophytes are well known to dermatologist and veterinarians. In addition, scientific literature suggests that drug resistance is on the rise in dermatophytes, although correlation between in vitro resistance and therapeutic failure is noted in a very small number of cases $[19,27,46,73-75]$. The cases of dermatophytoses in humans and animals described in this study were recalcitrant to treatment. We employed the broth microdilution methodologies using the CLSI M38 [76] standard to determine the MICs of the antifungal agents for the tested T. mentagrophytes clinical isolates. Our results indicate that the in vitro antifungal activity of the drug used in oral therapy were above $1 \mu \mathrm{g} / \mathrm{ml}$ in $15(82.8 \%)$ and $5(35.7 \%)$ cases of the human and animal infections, respectively. The cutoff value of MIC equal or higher than $1 \mu \mathrm{g} / \mathrm{ml}$ is considered in many scientific reports as an indicator of dermatophyte resistance to a given substance $[17-19,77]$. Nonetheless, the term "resistance" and the breakpoint of $1 \mu \mathrm{g} / \mathrm{ml}$ for dermatophytes need an appropriate context and the limitation of wide use is the lack of a clear link to clinical failure of treatment. Indira [78], Bhatia and Sharma [79], and Poojary [80] reported that $\mathrm{MIC}_{90}$ ranges for griseofulvin, itraconazole, and fluconazole were significantly higher against T. mentagrophytes isolates than against T. rubrum. Generally, Tamura et al. [81] suggested that T. mentagrophytes strains were more resistant to azoles than T. rubrum and the MIC ranges of the non-azole agents, i.e. amorolfine or terbinafine and butenafine, against Trichophyton spp. were relatively narrow compared to those of azole agents. However, increasing numbers of cases from Asian and European countries can be found in literature reports on dermatophytoses that are difficult to treat with terbinafine, which indicates that microbial resistance to this substance is on the rise $[27,54,55,82-86]$. Similarly, recent reports in literature have revealed that the trend of increasing MIC values for terbinafine in the T. mentagrophytes isolates is observed over the years. In the years 2009 to 2012 , the $\mathrm{MIC}_{50}$ for this drug was determined in the range of $0.06-0.125 \mu \mathrm{g} / \mathrm{ml}$ [87-90], and in 2018, this value increased up to $1 \mu \mathrm{g} / \mathrm{ml}$ [27]. Clinical evidence of relapse and incomplete mycological cure after standard oral terbinafine therapy, i.e. $250 \mathrm{mg}$, twice daily for 2 weeks have also been reported [91]. Sakai et al. [92] showed that the use of $250 \mathrm{mg}$ of terbinafine twice daily was appropriate for treatment of dermatophyte infections caused by T. mentagrophytes of animal origin with a MIC of $0.01 \mu \mathrm{g} / \mathrm{ml}$. In the present study, we observed that approximately $65 \%$ of human and $48 \%$ of animal isolates had a terbinafine MIC higher than $0.01 \mu \mathrm{g} / \mathrm{ml}$. Furthermore, the tissues infected by dermatophytes are avascular components of the skin; the time to attain therapeutic concentrations in them may differ greatly from plasma $[92,93]$. In consequence, a longer therapy strategy may be required to treat infections by T. mentagrophytes isolates with higher MICs. Unfortunately, this may not be clinically practical due to the possibility of drug-related side effects. Therefore, the choice of a proper drug for the therapy of dermatophyte infections is increasingly complicated and requires extensive knowledge. Our results indicate that there is no one-size-fits-all treatment pattern and no ideal antifungal substance, and the difficulties in therapy can be directly related to drug resistance in dermatophytes.

Interestingly, resistance to antifungal drugs seems to be of much less importance in connection with the failure of therapy in animals than in humans. This may be correlated with the frequently noted status of an animal asymptomatic carrier of dermatophytes [49, 53, 94]. Symptoms of infections in these animals can be observed only in certain host immune deficiency states, which are a major factor in subsequent treatment failures [32, 95]. Moreover, more intensive contact of animals with soil may favour the easy acquisition of infectious elements of dermatophytes, for which soil is one of the most important reservoirs [75, 96-98].

Finally, the difficulties in treating dermatophytoses may have a variety of causes that are not always related to the pathogen but result from the immunology of the host and his lifestyle. The increased frequency of reported refractory 
dermatophyte infections is now becoming a public health problem and the search for its key causes is necessary for new therapeutic approaches. Analysis of a large group of clinical isolates obtained from humans and animals with longlasting dermatophytoses indicates that fungal drug resistance is increasing. The causes of recalcitrant cases should be sought mainly in this phenomenon, and monitoring the susceptibility to antifungal drugs should be almost a routine examination at every emerging outbreak of the disease.

Authors' contributions Conceptualization: Sebastian Gnat, Dominik Lagowski; Methodology: Dominik Lagowski, Aneta Nowakiewicz, Lukasz Kopiński; Formal analysis and investigation: Dominik Łagowski, Sebastian Gnat, Marcelina Osińska; Writing - original draft preparation: Sebastian Gnat; Writing - review and editing: Dominik Łagowski.

Data availability All data generated or analysed during this study are included in this published article. Detailed data are available from the correspondence authors on request.

\section{Compliance with ethical standards}

Conflict of interest The authors declare that they have no conflict of interest.

Ethics approval The study was performed in accordance with the ethical standards as laid down in the 1964 Declaration of Helsinki and its later amendments.

Consent to participate Informed consent was obtained from all individual participants included in the study.

Open Access This article is licensed under a Creative Commons Attribution 4.0 International License, which permits use, sharing, adaptation, distribution and reproduction in any medium or format, as long as you give appropriate credit to the original author(s) and the source, provide a link to the Creative Commons licence, and indicate if changes were made. The images or other third party material in this article are included in the article's Creative Commons licence, unless indicated otherwise in a credit line to the material. If material is not included in the article's Creative Commons licence and your intended use is not permitted by statutory regulation or exceeds the permitted use, you will need to obtain permission directly from the copyright holder. To view a copy of this licence, visit http://creativecommons.org/licenses/by/4.0/.

\section{References}

1. Gnat S, Nowakiewicz A, Zięba P (2019) Taxonomy of dermatophytes - the classification systems may change but the identification problems remain the same. Adv Microbiol 58:49-58. https:// doi.org/10.21307/pm-2019.58.1.049

2. Weitzman I, Summerbell RC (1995) The dermatophytes. Clin Microbiol Rev 8:240-259. https://doi.org/10.1128/cmr.8.2.240

3. Bitew A (2018) Dermatophytosis: prevalence of dermatophytes and non-dermatophyte fungi from patients attending Arsho Advanced Medical Laboratory, Addis Ababa, Ethiopia. Dermatol Res Pract 2018:1-6. https://doi.org/10.1155/2018/8164757
4. Kannan P, Janaki C, Selvi G (2006) Prevalence of dermatophytes and other fungal agents isolated from clinical samples. Indian J Med Microbiol 24:212-215

5. Alemayehu A, Minwuyelet G, Andualem G (2016) Prevalence and etiologic agents of dermatophytosis among primary school children in Harari Regional State, Ethiopia. J Mycol 2016:1-5. https://doi. org/10.1155/2016/1489387

6. Ebrahimi M, Zarrinfar H, Naseri A et al (2019) Epidemiology of dermatophytosis in northeastern Iran; a subtropical region. Curr Med Mycol 5:16-21. https://doi.org/10.18502/cmm.5.2.1156

7. Havlickova B, Czaika VA, Friedrich M (2008) Epidemiological trends in skin mycoses worldwide. Mycoses 51:2-15. https://doi. org/10.1111/j.1439-0507.2008.01606.x

8. Gnat S, Łagowski D, Nowakiewicz A (2020) Major challenges and perspectives in the diagnostics and treatment of dermatophyte infections. J Appl Microbiol n/a:jam.14611. https://doi.org/10.1111/ jam. 14611

9. Nenoff P, Verma SB, Vasani R et al (2019) The current Indian epidemic of superficial dermatophytosis due to Trichophyton mentagrophytes - a molecular study. Mycoses 62:336-356. https://doi.org/10.1111/myc. 12878

10. Verma S (2017) Tinea pseudoimbricata. Indian J Dermatol Venereol Leprol 83:344-345. https://doi.org/10.4103/0378-6323. 187686

11. Singh A, Masih A, Monroy-Nieto J et al (2019) A unique multidrug-resistant clonal Trichophyton population distinct from Trichophyton mentagrophytes/Trichophyton interdigitale complex causing an ongoing alarming dermatophytosis outbreak in India: Genomic insights and resistance profile. Fungal Genet Biol 133: 103266. https://doi.org/10.1016/j.fgb.2019.103266

12. de Hoog GS, Dukik K, Monod M et al (2017) Toward a novel multilocus phylogenetic taxonomy for the dermatophytes. Mycopathologia 182:5-31. https://doi.org/10.1007/s11046-0160073-9

13. Begum J, Mir NA, Lingaraju MC et al (2020) Recent advances in the diagnosis of dermatophytosis. J Basic Microbiol 60:293-303. https://doi.org/10.1002/jobm.201900675

14. Gnat S, Łagowski D, Nowakiewicz A, Dyląg M (2019) Molekularne metody diagnostyki dermatomykoz - przegląd dostępnych technik oraz ocena ich zalet i wad w implementacji do rutynowego stosowania. Adv Microbiol 58:483-494. https:// doi.org/10.21307/PM-2019.58.4.483

15. Verrier J, Monod M (2017) Diagnosis of dermatophytosis using molecular biology. Mycopathologia 182:193-202. https://doi.org/ 10.1007/s11046-016-0038-Z

16. Rudramurthy S, Shaw D (2017) Overview and update on the laboratory diagnosis of dermatophytosis. Clin Dermatology Rev 1:3. https://doi.org/10.4103/cdr.cdr_35_17

17. Abastabar M, Jedi A, Guillot J et al (2019) In vitro activities of 15 antifungal drugs against a large collection of clinical isolates of Microsporum canis. Mycoses 62:1069-1078. https://doi.org/10. 1111/myc. 12986

18. Taghipour S, Shamsizadeh F, Pchelin IM et al (2020) Emergence of terbinafine resistant trichophyton mentagrophytes in iran, harboring mutations in the squalene epoxidase (Sqle) gene. Infect Drug Resist 13:845-850. https://doi.org/10.2147/IDR.S246025

19. Łagowski D, Gnat S, Nowakiewicz A, Osińska M (2020) Comparison of in vitro activities of 11 antifungal agents against Trichophyton verrucosum isolates associated with a variety hosts and geographical origin. Mycoses 63:294-301. https://doi.org/10. 1111/myc. 13042

20. Bouchara JP, Mignon B, Chaturvedi V (2017) Dermatophytes and dermatophytoses: a thematic overview of state of the art, and the directions for future research and developments. Mycopathologia 182:1-4. https://doi.org/10.1007/s11046-017-0114-z 
21. Singh B, Tripathy T, Kar B, Ray A (2020) Clinicomycological study of dermatophytosis in a tertiary care hospital in eastern India: a cross-sectional study. Indian Dermatol Online J 11:4650. https://doi.org/10.4103/idoj.IDOJ_62_19

22. Gnat S, Nowakiewicz A, Lagowski D, Zięba P (2019) Host- and pathogen-dependent susceptibility and predisposition to dermatophytosis. J Med Microbiol 68:823-836. https://doi.org/10. 1099/jmm.0.000982

23. Achterman RR, White TC (2012) Dermatophyte virulence factors: Identifying and analyzing genes that may contribute to chronic or acute skin infections. Int J Microbiol 2012:358305. https://doi.org/ $10.1155 / 2012 / 358305$

24. Sharma A, Chandra S, Sharma M (2012) Difference in keratinase activity of dermatophytes at different environmental conditions is an attribute of adaptation to parasitism. Mycoses 55:410-415. https://doi.org/10.1111/j.1439-0507.2011.02133.x

25. Viani FC, Dos Santos JI, Paula CR et al (2001) Production of extracellular enzymes by Microsporum canis and their role in its virulence. Med Mycol 39:463-468. https://doi.org/10.1080/mmy. 39.5.463.468

26. Elavarashi E, Kindo AJ, Rangarajan S (2017) Enzymatic and nonenzymatic virulence activities of dermatophytes on solid media. J Clin Diagn Res 11:DC23-DC25 10.7860/JCDR/2017/23147.9410

27. Singh A, Masih A, Khurana A et al (2018) High terbinafine resistance in Trichophyton interdigitale isolates in Delhi, India harbouring mutations in the squalene epoxidase gene. Mycoses 61:477-484. https://doi.org/10.1111/myc.12772

28. Sharma R, Adhikari L, Sharma RL (2017) Recurrent dermatophytosis: a rising problem in Sikkim, a Himalayan state of India. Indian J Pathol Microbiol 60:541-545. https://doi.org/10. 4103/IJPM.IJPM 83116

29. Ziółkowska G, Nowakiewicz A, Gnat S et al (2015) Molecular identification and classification of Trichophyton mentagrophytes complex strains isolated from humans and selected animal species. Mycoses 58:119-126. https://doi.org/10.1111/myc.12284

30. Khurana A, Masih A, Chowdhary A et al (2018) Correlation of in vitro susceptibility based on MICs and squalene epoxidase mutations with clinical response to terbinafine in patients with TINEa corporis/cruris. Antimicrob Agents Chemother 62(12):e01038e01018. https://doi.org/10.1128/AAC.01038-18

31. Gnat S, Nowakiewicz A, Lagowski D et al (2019) Multiple-strain trichophyton mentagrophytes infection in a silver fox (Vulpes vulpes) from a breeding farm. Med Mycol 57:171-180. https:// doi.org/10.1093/mmy/myy011

32. Łagowski D, Gnat S, Nowakiewicz A et al (2019) The prevalence of symptomatic dermatophytoses in dogs and cats and the pathomechanism of dermatophyte infections. Postępy Mikrobiol Adv Microbiol 58:165-176. https://doi.org/10.21307/pm-2019.58. 2.165

33. Nenoff P, Uhrlass S, Kruger C et al (2014) Trichophyton species of Arthroderma benhamiae - a new infectious agent in dermatology. $\mathrm{J}$ Dtsch Dermatol Ges 12:571-581. https://doi.org/10.1111/ddg. 12390

34. Varade RS, Burkemper NM (2013) Cutaneous fungal infections in the elderly. Clin Geriatr Med 29:461-478. https://doi.org/10.1016/j. cger.2013.01.001

35. Ohst T, Kupsch C, Gräser Y (2016) Detection of common dermatophytes in clinical specimens using a simple quantitative real-time TaqMan polymerase chain reaction assay. Br J Dermatol 174:602609. https://doi.org/10.1111/bjd.14198

36. Hoog GS, de Guarro J, Gené J, Figueras MJ (2000) Atlas of clinical fungi, 2nd edn. Centraalbureau voor Schimmelcultures (CBS), Utrecht

37. Gnat S, Nowakiewicz A, Ziółkowska G et al (2017) Evaluation of growth conditions and DNA extraction techniques used in the molecular analysis of dermatophytes. J Appl Microbiol 122: 1368-1379. https://doi.org/10.1111/jam.13427

38. Scott JA, Untereiner WA (2004) Determination of keratin degradation by fungi using keratin azure. Med Mycol 42:239-246. https:// doi.org/10.1080/13693780310001644680

39. Rippon JW, Varadi DP (1968) The elastases of pathogenic fungi and actinomycetes. J Invest Dermatol 50:54-58. https://doi.org/10. 1038/jid.1968.8

40. Gnat S, Lagowski D, Nowakiewicz A, Zięba P (2018) Phenotypic characterization of enzymatic activity of clinical dermatophyte isolates from animals with and without skin lesions and humans. J Appl Microbiol 125:700-709. https://doi.org/10.1111/jam.13921

41. Muhsin TM, Aubaid AH, Al-Duboon AH (1997) Extracellular enzyme activities of dermatophytes and yeast isolates on solid media. Mycoses 40:465-469. https://doi.org/10.1111/j.1439-0507.1997. tb00186.x

42. Vijayaraghavan P, Gnana S, Vincent P (2013) A simple method for the detection of protease activity on agar plates using Bromocresolgreen Dye. J Biochem Technol 4:628-630

43. Schaufuss P, Steller U (2003) Haemolytic activities of Trichophyton species. Med Mycol 41:511-516. https://doi.org/ 10.1080/1369378032000141462

44. Gnat S, Łagowski D, Nowakiewicz A, Zięba P (2019) The host range of dermatophytes, it is at all possible? Phenotypic evaluation of the keratinolytic activity of Trichophyton verrucosum clinical isolates. Mycoses 62:274-283. https://doi.org/10.1111/myc.12876

45. Köhler JR, Hube B, Puccia R et al (2017) Fungi that infect humans. Microbiol Spectr 5. https://doi.org/10.1128/microbiolspec.funk0014-2016

46. Martinez-Rossi NM, Bitencourt TA, Peres NTA et al (2018) Dermatophyte resistance to antifungal drugs: Mechanisms and prospectus. Front Microbiol 9:1108. https://doi.org/10.3389/fmicb. 2018.01108

47. de Aguiar Peres NT, Maranhão FCA, Rossi A, Martinez-Rossi NM (2010) Dermatophytes: host-pathogen interaction and antifungal resistance. An Bras Dermatol 85:657-667. https://doi.org/10. 1590/s0365-05962010000500009

48. Mourad A, Perfect JR (2018) Tolerability profile of the current antifungal armoury. J Antimicrob Chemother 73:i26-i32. https:// doi.org/10.1093/jac/dkx446

49. Łagowski D, Gnat S, Nowakiewicz A et al (2019) In search of the source of dermatophytosis: epidemiological analysis of Trichophyton verrucosum infection in llamas and the breeder (case report). Zoonoses Public Health 66:982-989. https://doi.org/10. 1111/zph. 12648

50. Leibner-Ciszak J, Dobrowolska A, Krawczyk B et al (2010) Evaluation of a PCR melting profile method for intraspecies differentiation of Trichophyton rubrum and Trichophyton interdigitale. J Med Microbiol 59:185-192. https://doi.org/10.1099/jmm.0. 013458-0

51. Ciesielska A, Kozłowska M, Gadzalski M et al (2014) Application of microsatellite-primed PCR (MSP-PCR) and PCR melting profile (PCR-MP) Method for intraspecies differentiation of dermatophytes. Pol J Microbiol 63:283-290. https://doi.org/10.33073/ pjm-2014-038

52. Gräser Y, Kühnisch J, Presber W (1999) Molecular markers reveal exclusively clonal reproduction in Trichophyton rubrum. J Clin Microbiol 37:3713-3717. https://doi.org/10.1128/jcm.37.11.37133717.1999

53. Gnat S, Łagowski D, Nowakiewicz A, Zięba P (2018) Tinea corporis by Microsporum canis in mycological laboratory staff: unexpected results of epidemiological investigation. Mycoses 61: 945-953. https://doi.org/10.1111/myc. 12832

54. Burmester A, Hipler UC, Hensche R et al (2019) Point mutations in the squalene epoxidase gene of Indian ITS genotype VIII T. mentagrophytes identified after DNA isolation from infected scales. 
Med Mycol Case Rep 26:23-24. https://doi.org/10.1016/j.mmcr. 2019.09.001

55. Hiruma J, Kitagawa H, Noguchi H et al (2019) Terbinafineresistant strain of Trichophyton interdigitale strain isolated from a tinea pedis patient. J Dermatol 46:351-353. https://doi.org/10. 1111/1346-8138.14809

56. Vermout S, Tabart J, Baldo A et al (2008) Pathogenesis of dermatophytosis. Mycopathologia 166:267-275. https://doi.org/ 10.1007/s11046-008-9104-5

57. Carvalho Reis AP, Correia FF, Jesus TM et al (2019) In situ immune response in human dermatophytosis: Possible role of Langerhans cells (CD1a+) as a risk factor for dermatophyte infection. Rev Inst Med Trop Sao Paulo 61:e56. https://doi.org/10.1590/ s1678-9946201961056

58. Cafarchia C, Iatta R, Latrofa MS et al (2013) Molecular epidemiology, phylogeny and evolution of dermatophytes. Infect Genet Evol 20:336-351. https://doi.org/10.1016/j.meegid.2013.09.005

59. Döğen A, Gümral R, Ilkit M (2015) Haemolytic and co-haemolytic (CAMP-like) activity in dermatophytes. Mycoses 58:40-47. https:// doi.org/10.1111/myc.12269

60. Martinez-Rossi NM, Peres NTA, Rossi A (2017) Pathogenesis of dermatophytosis: sensing the host tissue. Mycopathologia 182: 215-227. https://doi.org/10.1007/s11046-016-0057-9

61. Mignon B, Swinnen M, Bouchara JP et al (2008) Purification and characterization of a $315 \mathrm{kDa}$ keratinolytic subtilisin-like serine protease from and evidence of its secretion in naturally infected cats. Med Mycol 36:395-404. https://doi.org/10.1111/j.1365280x.1998.00179.x

62. Cafarchia C, Figueredo LA, Coccioli C et al (2012) Enzymatic activity of Microsporum canis and Trichophyton mentagrophytes from breeding rabbits with and without skin lesions. Mycoses 55: 45-49. https://doi.org/10.1111/j.1439-0507.2010.01997.x

63. Wawrzkiewicz K, Wolski T, Łobarzewski J (1991) Screening the keratinolytic activity of dermatophytes in vitro. Mycopathologia 114:1-8. https://doi.org/10.1007/BF00436684

64. Kaufman G, Horwitz B, Duek L et al (2007) Infection stages of the dermatophyte pathogen Trichophyton: microscopic characterization and proteolytic enzymes. Med Mycol 45:149-155. https:// doi.org/10.1080/13693780601113618

65. Sharma M, Sharma M, Rao VM (2011) In vitro biodegradation of keratin by dermatophytes and some soil keratinophiles. Afr J Biochem Res 5:1-6

66. Mercer DK, Stewart CS (2019) Keratin hydrolysis by dermatophytes. Med Mycol 57:13-22. https://doi.org/10.1093/mmy/ myx 160

67. Zhang M, Jiang L, Li F et al (2019) Simultaneous dermatophytosis and keratomycosis caused by Trichophyton interdigitale infection: a case report and literature review. BMC Infect Dis 19:983. https:// doi.org/10.1186/s12879-019-4612-0

68. Das S, De A, Saha R et al (2020) The current indian epidemic of dermatophytosis: A study on causative agents and sensitivity patterns. Indian J Dermatol 65:118. https://doi.org/10.4103/ijd.ijd_ 203_19

69. Grumbt M, Monod M, Yamada T et al (2013) Keratin degradation by dermatophytes relies on cysteine dioxygenase and a sulfite efflux pump. J Invest Dermatol 133:1550-1555. https://doi.org/10. 1038/jid.2013.41

70. Gnat S, Łagowski D, Nowakiewicz A, Dylag M (2020) Clinically used and potential antimycotics in the context of therapy of dermatomycoses. Postępy Mikrobiol - Adv Microbiol 59:63-74. https://doi.org/10.21307/pm-2020.59.1.006

71. Dogra S, Shaw D, Rudramurthy S (2019) Antifungal drug susceptibility testing of dermatophytes: Laboratory findings to clinical implications. Indian Dermatol Online J 10:225. https://doi.org/10. 4103/idoj.idoj_146_19
72. Rajagopalan M, Inamadar A, Mittal A et al (2018) Expert Consensus on The Management of Dermatophytosis in India (ECTODERM India). BMC Dermatol 18:6. https://doi.org/10. 1186/s12895-018-0073-1

73. Baghi N, Shokohi T, Badali H et al (2016) In vitro activity of new azoles luliconazole and lanoconazole compared with ten other antifungal drugs against clinical dermatophyte isolates. Med Mycol 54:757-763. https://doi.org/10.1093/mmy/myw016

74. Vandeputte P, Ferrari S, Coste AT (2012) Antifungal resistance and new strategies to control fungal infections. Int J Microbiol 2012: 713687. https://doi.org/10.1155/2012/713687

75. Gnat S, Łagowski D, Nowakiewicz A, Dylag M (2020) Unusual dermatomycoses caused by Nannizzia nana: the geophilic origin of human infections. Infection. https://doi.org/10.1007/s15010-02001416-5

76. CLSI (2008) Reference method for broth dilution antifungal susceptibility testing of filamentous fungi; Approved Standard-Second Edition, 2nd ed. Clinical and Laboratory Standards Institute, Wayne

77. Maurya VK, Kachhwaha D, Bora A et al (2019) Determination of antifungal minimum inhibitory concentration and its clinical correlation among treatment failure cases of dermatophytosis. J Family Med Prim Care 8:2577-2581 10.4103/jfmpc.jfmpc_483_19

78. Indira $\mathrm{G}$ (2014) In vitro antifungal susceptibility testing of 5 antifungal agents against dermatophytic species by CLSI (M38-A) micro dilution method. Clin Microbiol Open Access 03 10.4172/ 2327-5073.1000145

79. Bhatia VK, Sharma PC (2015) Determination of minimum inhibitory concentrations of itraconazole, terbinafine and ketoconazole against dermatophyte species by broth microdilution method. Indian J Med Microbiol 33:533-537. https://doi.org/10.4103/ 0255-0857.167341

80. Poojary S, Miskeen A, Bagadia J et al (2019) A study of In vitro antifungal susceptibility patterns of dermatophytic fungi at a tertiary care center in Western India. Indian J Dermatol 64:277-284. https:// doi.org/10.4103/ijd.IJD 45618

81. Tamura T, Asahara M, Yamamoto M et al (2014) In vitro susceptibility of dermatomycoses agents to six antifungal drugs and evaluation by fractional inhibitory concentration index of combined effects of amorolfine and itraconazole in dermatophytes. Microbiol Immunol 58:1-8. https://doi.org/10.1111/1348-0421. 12109

82. Bishnoi A, Vinay K, Dogra S (2018) Emergence of recalcitrant dermatophytosis in India. Lancet Infect Dis 18:250-251. https:// doi.org/10.1016/S1473-3099(18)30079-3

83. Hsieh A, Quenan S, Riat A et al (2019) A new mutation in the SQLE gene of Trichophyton mentagrophytes associated to terbinafine resistance in a couple with disseminated tinea corporis. J Mycol Med 29:352-355. https://doi.org/10.1016/j.mycmed.2019. 100903

84. Rudramurthy SM, Shankarnarayan SA, Dogra S et al (2018) Mutation in the squalene epoxidase gene of trichophyton interdigitale and trichophyton rubrum associated with allylamine resistance. Antimicrob Agents Chemother 62(5):e02522-e02517. https://doi.org/10.1128/AAC.02522-17

85. Saunte DML, Hare RK, Jørgensen KM et al (2019) Emerging terbinafine resistance in Trichophyton: clinical characteristics, squalene epoxidase gene mutations, and a reliable EUCAST method for detection. Antimicrob Agents Chemother 63(10):e01126e01119. https://doi.org/10.1128/AAC.01126-19

86. Yamada T, Maeda M, Alshahni MM et al (2017) Terbinafine resistance of Trichophyton clinical isolates caused by specific point mutations in the squalene epoxidase gene. Antimicrob Agents Chemother 61(7):e00115-e00117. https://doi.org/10.1128/AAC. 00115-17 
87. Ataides FS, Chaul MH, El Essal FE et al (2012) Antifungal susceptibility patterns of yeasts and filamentous fungi isolated from nail infection. J Eur Acad Dermatol Venereol 26:1479-1485. https:// doi.org/10.1111/j.1468-3083.2011.04315.x

88. Zalacain A, Obrador C, Martinez JP et al (2011) Characterization of the antimicrobial susceptibility of fungi responsible for onychomycosis in Spain. Med Mycol 49:495-499. https://doi.org/ 10.3109/13693786.2010.541949

89. Bueno JG, Martinez C, Zapata B et al (2010) In vitro activity of fluconazole, itraconazole, voriconazole and terbinafine against fungi causing onychomycosis. Clin Exp Dermatol 35:658-663. https:// doi.org/10.1111/j.1365-2230.2009.03698.x

90. Mota CRA, Miranda KC, Lemos JDA et al (2009) Comparison of in vitro activity of five antifungal agents against dermatophytes, using the agar dilution and broth microdilution methods. Rev Soc Bras Med Trop 42:250-254. https://doi.org/10.1590/S003786822009000300003

91. Majid I, Sheikh G, Kanth F, Hakak R (2016) Relapse after oral terbinafine therapy in dermatophytosis: a clinical and mycological study. Indian J Dermatol 61:529-533. https://doi.org/10.4103/ 0019-5154.190120

92. Sakai MR, May ER, Imerman PM et al (2011) Terbinafine pharmacokinetics after single dose oral administration in the dog. Vet Dermatol 22:528-534. https://doi.org/10.1111/j.1365-3164.2011. 00985.x

93. Faergemann J, Zehender H, Millerioux L (1994) Levels of terbinafine in plasma, stratum corneum, dermis-epidermis (without stratum corneum), sebum, hair and nails during and after $250 \mathrm{mg}$ terbinafine orally once daily for 7 and 14 days. Clin Exp Dermatol 19:121-126. https://doi.org/10.1111/j.1365-2230.1994.tb01138.x

94. Ilhan Z, Karaca M, Ekin IH et al (2016) Detection of seasonal asymptomatic dermatophytes in Van cats. Braz J Microbiol 47: 225-230. https://doi.org/10.1016/j.bjm.2015.11.027

95. Moriello KA, Coyner K, Paterson S, Mignon B (2017) Diagnosis and treatment of dermatophytosis in dogs and cats.: Clinical Consensus Guidelines of the World Association for Veterinary Dermatology. Vet Dermatol 28:266-268. https://doi.org/10.1111/ vde. 12440

96. Gnat S, Łagowski D, Nowakiewicz A, Dylag M (2019) Tinea corporis caused by Trichophyton equinum transmitted from asymptomatic dogs to two siblings. Braz J Microbiol. https://doi.org/10. 1007/s42770-019-00204-0

97. Dehghan P, Yousefi Jalali S, Chadeganipour M (2019) Frequency distribution of keratinophilic dermatophyte fungi from the soil of different zones in isfahan using morphological and molecular methods. Adv Biomed Res 8:38. https://doi.org/10.4103/abr.abr 3119

98. Singh I, Kushwaha RKS (2010) Dermatophytes and related keratinophilic fungi in soil of parks and agricultural fields of Uttar Pradesh, India. Indian J Dermatol 55:306-308. https://oi. org/10.4103/0019-5154.70700

Publisher's note Springer Nature remains neutral with regard to jurisdictional claims in published maps and institutional affiliations. 